\title{
Klassikern
}

\section{Att ställa ut historia}

Per-Uno Ågren

\section{I svensk museipedagogisk debatt ersätter man numera begreppet "permanenta utställningar" med "basutställningar" för att betona vikten av att betrakta också presentationen av ett museums huvudsamlingar som en tidsbunden företeelse, som måste förändras, som inte får låsas genom en permanent arkitektonisk infattning.}

\section{TRADITIONERNA}

$\AA$ ena sidan finns konstmuseernas estetiska subtiliteter, å den andra de naturhistoriska museernas klassifikationslidelse och dioramor. Mellan dem de kulturhistoriska museerna, som kränger än åt ena än åt andra sidan.

1. Den estetiserande traditionen vill göra museerna till "skönhetens tempel", utställningarna till en konstform. Den hör självfallet samman med konstmuseerna, men har kommit att få vidare tillämpning, framför allt vid etnografiska och kulturhistoriska museer, där en estetisk värdering av föremålen påverkat både insamling och utställning. Innehållet har underordnats ett nationellt eller nationalromantiskt syfte: att exponera det skönaste och yppersta av vad den egna kulturen förmått ska väcka nationell stolthet och lojalitet.

Målsättningen är framträdande i svenskt museitänkande i slutet av 1800-talet, men formuleras ännu i landshövdingens tal vid invigningen av museet i Umeå 1926: ”... och det är kanske inte för mycket sagt om man i en fördjupad kännedom om äldre tiders seder och bruk ser den solidaste grundvalen för kärleken till hembygden ... Det är en allmänt gjord iakttagelse att det skönas åskådande och begrundande är ett kraftigt medel till sinnets harmoniska utveckling... Konsten har till uppgift människosläktets förädling”. - Motiv av den arten är i vår tid en viktig drivfjäder vid uppbyggnaden av museer i exempelvis Afrikas nya statsbildningar.

2. Den typologiska traditionen. Metoden innebär att materialet ordnas efter ett abstrakt schema, som det är utställningens ändamål att belysa - eller kanske t.o.m att bevisa. Metoden har - när det gäller kulturhistoriskt material som förutsättning Tomsens och Montelius' typologiska system för arkeologiskt material. Den har framför allt tillämpats vid de stora arkeologiska museerna, men präglar också många presentationer av etnografiskt material. Det är en de vetenskapliga museernas metod, ett sätt att analysera föremål som historiskt källmaterial för att beskriva kulturer utan skriftliga urkunder. Den pedagogiska tanken är att den systematik man valt är tillräckligt intressant som motivation för besökarna. 
3. Dioramorna - miljöutställningen. Dioramat är ett försök att i museet visa djur eller föremål i sin naturliga miljö. Man vill sätta in museets material i ett tid/rumsammanhang. Metoden har kommit till användning - utom i naturhistoriska museer (senast på ett utomordentligt sätt i Bent Jørgensens nyuppställning av Universitetets zoologiska museum i Köpenhamn) - i folkkulturmuseer och etnografiska museer.

Miljöutställningen kan lätt kombineras med de båda tidigare - antingen miljön får exemplifiera en tid, en stil, en region eller den återskapas på grund av estetiska värden i miljöhelheten. Kombinationen av motiv är tydlig redan när den provas av Artur Hazelius vid uppbyggnaden av Nordiska museet, där bondstuguinteriörerna gjordes till tablåer, "frusna ögonblick", med düsseldorfmålarnas bilder som förlagor.

"Här började jag genast", skriver Hazelius, "utföra den plan, som skulle giva museet en egendomlig prägel, och som enligt min övertygelse mer och mer måste vinna i efterföljd i andra stora etnografiska och kulturhistoriska museer. För att föremålen måtte väcka större intresse borde man se dem i deras användning, se bohagen i själva stugorna, se huru dräkterna burits. Hela folklivsbilder borde framställas, varigenom ett livligt intryck kunde vinnas av befolkningens lynne och seder".

I folkkulturmuseerna avlänkas metoden så småningom på friluftsmuseerna, som erbjuder bättre förutsättningar för att visa miljöer i rätt skala och med riktiga rumssammanhang samt erbjuder bakgrunder, scenrum, för levande aktiviteter. Hazelius: "Skansen strävar mer och mer efter att varda ett levande museum - ett museum som ej endast visar byggnader och bohag - det vill vid sidan av detta ännu mera. Det vill framställa folklivet i levande drag".

Den systematiska materialpresentationen kommer därefter att prägla de egentliga muse-

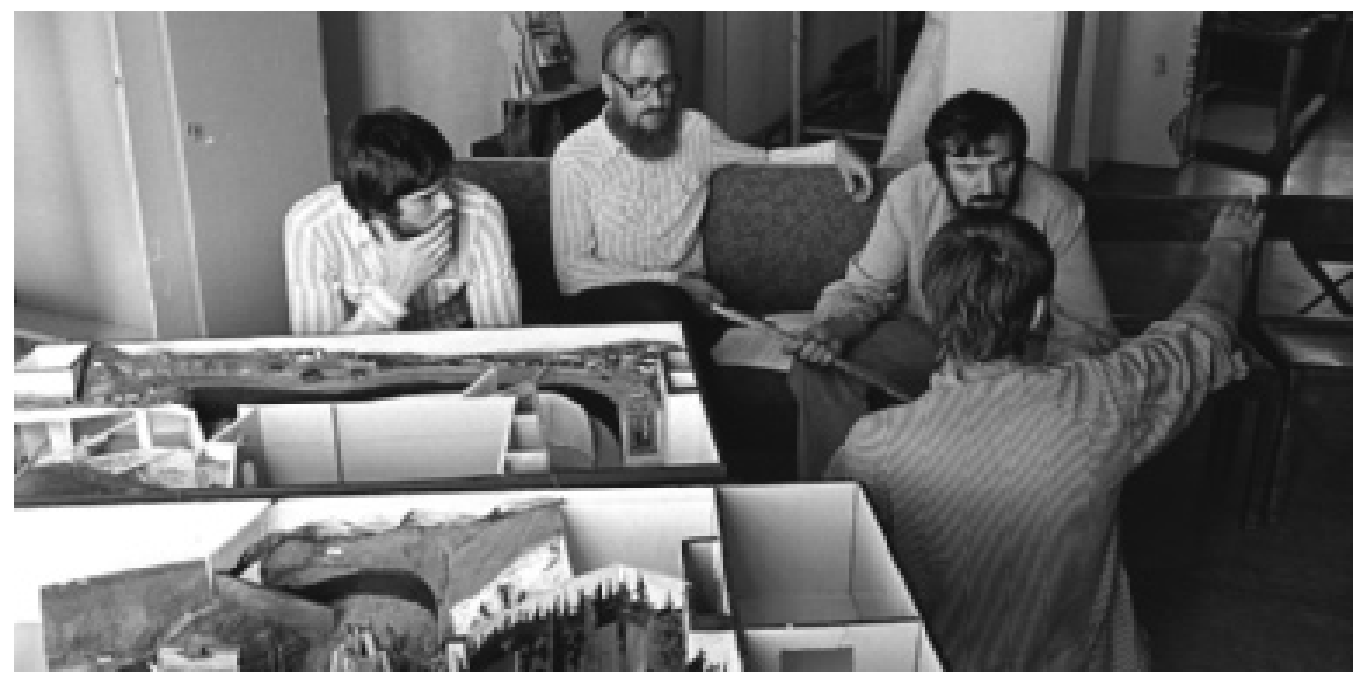

Forberedelser til den store ombygning: Fra venstre Lennart Jareman, museumstekniker, Per-Uno Agren, Göran Carlsson og med ryggen til Anders Aberg. I forgrunden model af den ny basisudstilling, som gjorde Västerbottens Museum berømt. Foto: Ole Strandgaard 1974. 
ala utställningarna, eftersom sakforskningens resultat lättare kan åskådliggöras med isolerade föremålssammanställningar än med miljöer. Till att miljöutställningarna föll i vanrykte bidrog kanske att Hazelius' tablåer liksom düsseldorfarnas tavlor uttryckte en sentimental värdering av folkkulturen, som innebar en eskapism från den dåtida sociala verkligheten i ett industriellt/urbant samhälle. Fredrik Böök: "Artur Hazelius' hela fantasiinriktning och smak bildar en parallell till den nationella romantiken, han ville ge sin samtid en historisknationell väckelse. Han eftersträvade en etnografisk patriotism och hans verk gav stöd åt den estetiska kärleken till det förflutna”.

Utställningarna blev i stället en konkretisering av sakforskarnas skrifter. Man reagerade mot folklivsromantikens sentimentala förfalskningar och den skevhet i förhållande till den historiska verkligheten, som miljötablåerna representerade, de fick vara hur minutiöst de-

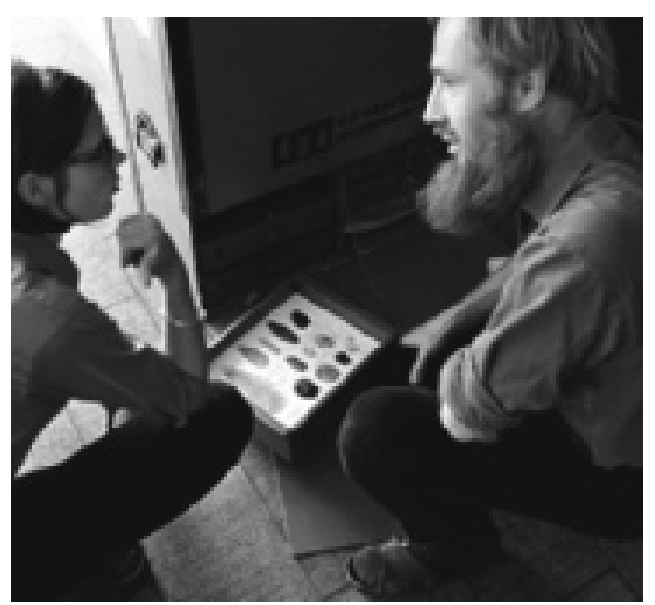

Per-Uno demonstrerer Västerbotten Museums vandrekasser med samlinger til udlan til skolerne for Kirsten Strandgaard, Unesco Skoleprojekt, Moesgärd. Foto: Ole Strandgaard 1971. taljstuderade som helst. Miljömetodiken fick vika för föremålssystematiken.

Härvid försummades en viktig och för Hazelius central synpunkt - utställningens uppgift gentemot publiken. Miljöerna hade bildat underlag för upplevelser, hade varit stämningsskapande, suggestiva, i första hand velat förmedla ett mänskligt innehåll, $i$ andra hand informera om komponenterna i en till tid och rum fixerad historisk miljö. Med den systematiska presentationen redovisar man en historisk kunskap om föremålet, man har abstraherat det från miljösammanhanget.

Men Per Wästberg har gjort en väsentlig iakttagelse när han i sin uppsats om museer och deras publik ("Det sällsamma vardagsrummet") konstaterar att "endast det har innebörd som står i relation till det levande". Samma insikt som den schweiziske museiledaren Jean Gabus uttryckt med orden "Utställningen skall liksom varje äkta konstverk åstadkomma det mirakel som består i att en känsla av liv förmedlas genom livlösa ting".

\section{ATt Veta VEM MAN TALAR MED}

Det är nödvändigt att i varje utställningsföretag definiera den publikgrupp man vänder sig till. Kan visningarna, denna museernas ständiga översättningsverksamhet, elimineras? Verbalt byggs de miljöer upp, som föremålen saknar, fogas samman till begripliga gestalter.

Vår viktigaste målgrupp är grundskolans mellanstadium. En arbetshypotes: att utställningar som kan kommunicera med ungdomar på 10-14 år också når huvudparten av vuxenpubliken.

Skillnaden mellan upplevelseerfarenhet och läserfarenhet: Ledan som silar genom skolan på alla nivåer och omärkligt fyller klassrummen, ledan vid ordströmmen, bildströmmen 
140 distribuerad med ständigt mer fulländade läromedel. Ditt barn i första klass som frågar om det är lång tid kvar i skolan ...

Det tredimensionella föremålet och miljön finns i toppen på pedagogens konkretiseringspyramid och upplevs starkare än pedagogiska hjälpmedel på lägre nivåer (längst ner det skrivna ordet). Konsekvensen blir för utställningens del att den i så stor utsträckning som möjligt bör fungera utan stöd i text, att de enskilda föremålen och deras innebörd bör vara möjlig att uppfatta genom det sätt varpå de exponeras, sin visuella kontext. "Principen skall vara, att en information, som kräver mer än ett visst - ringa - antal ord, hör hemma i en bok och inte i ett museum, vars upplevelsevärld måste vara en helt annan” (Bent Jørgensen).

\section{MILJÖMETOdENS RENÄSSANS}

Just nu finns exempel på en renässans för miljömetoden: Riksutställningars projekt kring industrialismens genombrott. Göteborgare i ett rum och kök i Göteborgs historiska museum härom året.

Miljömetoden är den bästa för att levandegöra en historisk verklighet så lättuppfattat visuellt som möjligt. Att förmedla en historisk känsla - inte att i och för sig och isolerat illustrera en teknikhistorisk, en agrarhistorisk, en socialhistorisk etc. utveckling, utan att ha hela den mänskliga situationen i blickpunkten. Det kulturhistoriska dioramat skulle också rymma den kulturekologiska aspekten: den naturmiljö som är samhällets, kulturens förutsättning (redan förverkligat i Milwaukee-museets utställningar, enligt bilder och beskrivningar).

Men också miljöbilderna är statiska. Man kan införa ett dynamiskt element - monitorer med vars hjälp filmer kan visas om miljöerna i användning - och ljudband?

Ett centralt problem blir att ta steget från ett åskådliggörande till ett levandegörande. Något som förutsätter en gemensam referensram för producenter och publik, och därför kräver att historien från tid till annan omformuleras, omvärderas - dvs. utställningarna görs om så att i nuet väsentliga aspekter i historien

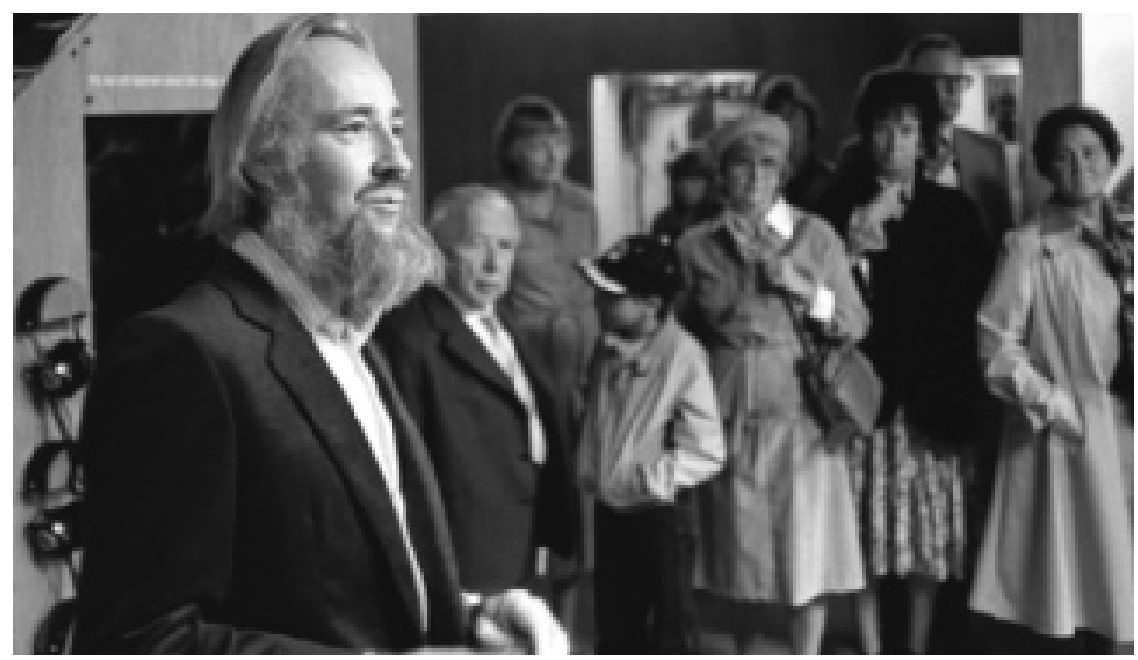

Per-Uno Agren taler ved abningen af anden sektion af basisudstillingen om oldtid, renavl og nybyggerliv, efteraret 1980. Foto: Ole Strandgaard. 
tas fram. Detta är förutsättningen för att en meningsfull relation till publiken ska kunna uppstå, en relation som leder till förståelse inte bara av historien, utan också av den egna situationen. Museimannen, som genom att välja utställningar, ämne och form för egna produktioner, är en opinionsbildare, attitydformare med utställningen som medium. Han måste därför vara väl nutidsorienterad och hela tiden söka relationerna till publikens erfarenheter, söka problemens historiska förutsättningar, belysa dem med sitt material och dra fram gångna generationers redan glömda erfarenheter.

Museet, utställningen, fixerar besökaren vid den bild av en tid, en trakt, en miljö, som utställningen beskriver. Producenten måste ständigt fråga sig: är den bild jag ger verkligen representativ, väsentlig för den kultursituation, som mitt material hänför sig till?

Men en miljöutställnings syfte är att ge suggestion till upplevelse, inte främst att ge en detaljerad miljörekonstruktion. Man kan arbeta med antydningar, stimulera besökarnas upptäckarinstinkt. I miljögestaltningen, före-

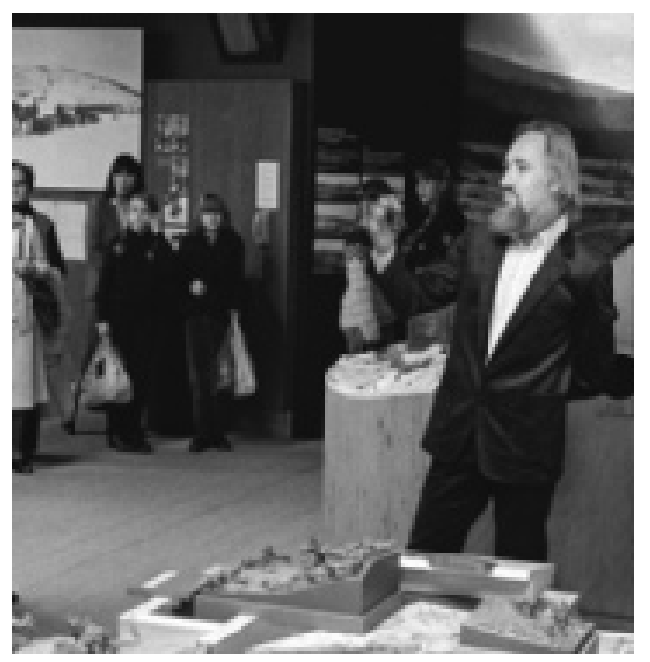

målsexponeringen, avslöjar sig utställnings141 producentens kapacitet i förmågan att förmedla övertoner. En observation av Per Wästberg: "Museet sysslar med det synliga. Bakom skymtar idéerna: varför gjordes detta, varför blev det så?" Se där övertoner att visuellt konkretisera!

\section{MUSEIPEDAGOGIK}

Det gäller alltså föremålens och miljöernas upplevelseskapande möjligheter i den pågående museipedagogiska debatten i utlandet och i Sverige. En stimuleringsdel, ett upplevelsemoment är enligt gängse inlärningsmodeller utgångspunkten för en "motiverad", meningsfull, kunskapsförmedling. Museal verksamhet med utställningar är principiellt en undervisningsverksamhet. Utställningens primära uppgift bör vara att fungera som stimuleringsdel, att erbjuda en sinnlig verklighetsupplevelse, som skapar nyfikenhet för historisk problemanalys. Många museer dränker överambitiöst sina besökare i information, som skapar hämningar och skuldkänslor i stället för nyfikenhet.

De kulturhistoriska museerna är miljöhistoriska centraler - och bör ha ett miljödokumenterande ansvar i nuet! Ett problem med miljöbyggen som utställningsform är det större utrymmesbehovet jämfört med den systematiska utställningstypen. Den kompletterande miljöhistoriska dokumentationen måste därför göras lättillgänglig. Miljöutställningen måste kompletteras med studierum, i vilket museet kan fungera som "tredimensionell uppslagsbok", tillhandahålla text-, bild- och ljuddokument.

Den tredje komponenten i det museipedagogiska arbetet är en aktivitetsdel. Utställningen måste ha ett utrymme, där besökarna får pröva roll- och verkstadsaktiviteter. 
142 Vid etnografiska museet i Leiden, där man under många år och mer målmedvetet än på andra håll arbetat med att introducera kulturkunskap i skolorna, tog man hand om skolklasser, som under en hel vecka vistades i museet och där ur olika synpunkter studerade en främmande kultur. Arbetet mynnade ut i "etnodramer", där eleverna fick gestalta situationer i den kultur de studerat i museet. Genom att på ett tidigt stadium av studieprojektet tilldelas en roll stimulerades den enskilde deltagaren att själv samla den information, som behövdes för att klara uppgiften (beskrivs av H. H. Frese i "Anthropology and the public: the role of museums"; liknande försök vid Geffrye museum i London beskrivs av Molly Harrison i "Changing museums").

Också verkstadsaktiviteter har stor betydelse i uppgiften att levandegöra. Hantverksprocedurer, arbetsförlopp, som ligger bakom de materiella produkter som exponeras, kan visserligen visas i bild och film, men att själv få pröva redskap, verktyg och metoder ger den värdefullaste erfarenheten.

Att vidmakthålla det manuella arbetets traditioner, det praktiska-tekniska kunnandet bör också vara en museernas uppgift. Inte bara en bevaringsuppgift, utan en traditionsförmedlande, pedagogisk uppgift.

\section{Nostalgins Legitima hemVist?}

Konkurrensen mellan massmedia i vår tid har lett till en fragmentisering och nivellering av informationen. Museerna verkar med eller mot sin vilja i denna konkurrenssituation.

Man kan som Per Wästberg uppfatta museet som "vår tids profana kyrka, nostalgins legitima hemvist". Men han konstaterar också att museet har en informerande uppgift och "för att informationen ska gå fram krävs att den bjuder en upplevelse", alltså en partiell identifikation, "en relation till det levande", till nuet.

S. Cauman har i sin bok om den framstående tyske museimannen Alexander Dorner, "Das lebende Museum", också uppfattat dualismen: "I stället för att museet blir en kraft som påverkar livet, blir det en tillflyktsort från dess krav, en stillaståendets Oas i en föränderlig värld". Men så bör det inte fungera: "Det levande museet håller historia och samtid tillsammans, inte så att det förgångna kväver det nuvarande, utan snarare så att dess förbindelser med nuet belyses. Rörelserna i nuet är de krafter, som förändrar oss och vår situation, historiens lämningar blir vägen till förståelse av de utvecklingsprocesser vi bevittnar i nutiden ... Det levande museet är den scen, där människans skapande idéer framträder och konfronteras".

EIler varför inte använda Sigurd Curmans formulering (i talet vid invigningen av Västerbottens läns museum 1943): "Ett kulturhistoriskt museums uppgift är att vara en levande institution, som genom föremålens sakkunniga bearbetning, konservering, uppställning och beskrivning tillvaratar dessas värde och genom deras insättande i större sammanhang gör föremålen förståeliga såsom länkar i en levande utveckling, ej som lösryckta kuriositeter... Museet skall ej vara ett mausoleum över död kultur utan en eggande lärodikt över en urgammal kulturs alltjämt friska kraft till utveckling och förnyelse. Ett museum, som så fattar sin uppgift, har i sanning en stor och levande social uppgift i vårt samhälle".

"Att ställa ut historia" stod oprindeligt i det svenske designtidsskrift Form 1972:4 side 178-81. 